\title{
On-Line and Back at S.F.U.
}

\author{
M. SANDERSON: Simon Fraser University
}

Simon Fraser University library began operation with an automated circulation system. After deliberation, it mounted the first phase of a two-phase on-line circulation system. A radically revised loan policy caused the system design and assumptions to be called into question. A cheaper, simpler, and more effective off-line system eventually replaced the on-line system. The systems, fiscal, and administrative implications of this decision are reviewed.

\section{THE ORIGINAL SYSTEM}

When Simon Fraser University (SFU) library opened in 1965, circulation of materials was handled by an automated system. Briefly the method of operation was as follows: to borrow a book, the patron presented a laminated plastic card which had his borrower number and borrower class (faculty, staff, graduate, undergraduate) punched in it. The book itself contained a keypunched card holding the book's class number and brief author and title information. The book card and the patron's badge were fed into an IBM 1031 data collection terminal. The terminal transmitted the information to an IBM 1034 card punch which punched out a card containing the information from the book card, the patron's borrower number, and the date borrowed. At the end of the day, these transaction cards were used to update the Loan Master File. The Loan Master File produced daily a list of all material on loan, and fine and overdue notices for dispatch to patrons. Payment cards for fines were also produced daily by the system; these cards were used to cancel fines from the file upon payment of the fine. The Loan Master File and the daily circulation listing also contained records of all materials on reserve. Separate listings were available weekly showing reserve books and reserve photocopied material. At the end of each semester a list was produced of all students owing more than $\$ 2$ in fines for the purpose of withholding grades until such time as fines were paid.

\section{REASONS FOR GOING ON-LINE}

The possibility of implementing an on-line system in one of the SFU departments was first discussed in early summer 1968.

It was accepted by the Computing Centre management and the nonacademic department heads that:

1. The use of on-line processing generally was increasing rapidly.

2. The level of sophistication of these systems was not high. 
3. There was a shortage of people competent to design, implement, and maintain sophisticated on-line systems.

4. A demand for on-line processing at SFU would develop.

5. SFU would probably move with the general trend toward increased use of on-line systems, and an on-line system ought to be initiated to develop local expertise in anticipation of demand.

After further discussion, it was agreed that the department wishing to develop the first on-line system must be able to satisfy the following prerequisites:

1. The system should encompass the beginning and the end of a clearly defined process.

2. The system should require the simultaneous use of one or more files by two or more terminals.

3. The system should use relatively large files with a high inquiry and update rate.

4. The system should satisfy genuine objectives of the application department.

A survey of the departments showed that the library was the logical choice because:

1. It could satisfy the prerequisites.

2. It had experience with automated systems.

3. Batch-processing in the Loan Division could be extended to the on-line mode using the existing line of equipment.

4. The library administration was prepared to make an immediate commitment of resources to the project.

The library's objectives were as follows:

1. Inventory Control-To gain statistics about the use of the collection. Such data were available under batch processing for the general collection, but not for the reserve collection, which, with its loan periods of two hours, four hours, one day, and three days, was handled manually.

2. Inventory Usefulness-To determine how the library is being used and by whom. This information is essential in order to ensure that collection building is a reflection of the realities of the education process of the institution.

3. Increased Service-By definition, the library is a service institution. If the automated system in batch mode allowed us to speed up the transaction process to handle large volume circulation, and allowed us to produce overdue notices, bills, and statistics, thereby increasing both the efficiency and service of the Loan Division, then we were satisfying a built-in library objective by implementing data processing in batch mode in the Loan Division. If the on-line system could give our users instant information on the status of books, then that function becomes a service objective. At SFU, the loan period and penalties for overdue books are the same for all classes of borrowers. The library has never been an enthusiastic supporter of the fines system because 
of the general antagonism it creates and because it favors the borrower who can afford to pay. Unfortunately, there was no acceptable way to force faculty to pay fines. It was thought that the on-line system was the only way to support a system of suspension of borrowing privileges for failure to return books, in lieu of the fines system.

4. Cooperation-It was agreed between the three universities of British Columbia (Simon Fraser University, University of Victoria, and University of British Columbia) that the storage of low-use material in a cooperatively supported lending/storage facility would save in the order of $\$ 800,000$ per year. It was felt that the on-line system would provide useful statistics for this purpose.

5. Future Development-It was thought that the on-line system, with its statistics-gathering potential, was a necessary preliminary to the cooperative shelflist conversion of the three universities, in turn thought necessary to provide the kind of bibliographic information to allow collaborative collection building.

The reasons why the above justifications later turned out to be invalid are given in a subsequent section.

PHASE I OF THE ON-LINE SYSTEM (Abbreviated system flowcharts of the various stages are shown in Appendix 4)

The purpose of Phase I was to put the general collection on-line in enquiry mode only with batch updating every three hours-on-line updating was to wait until Phase II.

In April 1969, one full-time programmer analyst and one part-time systems analyst began work on the first phase of the on-line system, using three IBM 2260 graphic display terminals.

Problems with PGAM, the PL/I graphic access method interface program, and multitasking support allowing the use of more than one terminal at a time (it was easy to get one terminal going) meant that by April 1970 the system was just struggling into life. There followed a period of parallel rumning which was unexpectedly long as a result of some of the problems peculiar to on-line systems (e.g. system down-time; designing a really effective back-up system to prevent loss of data). This phase lasted until October 1970. By July 1971 it had become apparent that the system was not cost-effective and in August 1971 the system was taken down and replaced by a revised version of the old batch system. The reasons and costs are given in a later section.

There were three display terminals in the Loan Division, two for patrons, one for staff, giving the following capabilities:

Patron-When the patron typed in the class number of the book he was looking for, according to instructions appearing on the terminal's screen, the information was transmitted to the computer program which searched the on-line Loan Master File for the required class number. If the book was on loan, a message appeared on the screen giving the class number, borrower number, due date, and whether a hold had been placed on the book. 
If the book was not on loan or on reserve, or being repaired, or in cataloging, a message to this effect was displayed. If the patron made any errors in his use of the terminal, error routines in the program displayed messages giving corrective procedures.

Staff-By use of a special password, staff members could access different modules of the enquiry program. A status query by a staff member would result in all copies of a particular class number being displayed serially on the screen, and since fines and overdues were held on the master file, this type of information was also displayed. Other routines available to staff members allowed holds to be placed on books or removed, renewals to be made, and the passwords to be altered. Although passwords were a closely guarded secret, it was felt necessary to be able to change passwords in the event of their being learned by unauthorized users.

Since on-line updating was not to be incorporated until Phase II, the 1034 transaction cards were input every three hours and the Loan Master File updated in batch mode.

File structure for Phase I was based on an indexed sequential type of access to a Loan Master File which contained one 100-byte record per book on loan, one record per fine and one record per reserve book. In this way, the Loan Master File was in the same format as in the batch system. Access to the file began with a program check of a small table held in core storage which gave ranges of class numbers with entry points to an index table. Taking the appropriate entry point, the index table stored on dise was accessed. This gave the class number which headed each track for the Loan Master File. The index table was scanned for the appropriate track. Each track of the Loan Master File contained fifty-four records with eighteen spaces for updates. Whenever a record was changed or a new loan inserted, the new record was inserted in the update area. At the end of the day, the file was stripped of its update records and the old batch update program was used to update the Loan Master File. The Loan Master File was rewritten to disc the following morning ready for the day's updates. Total file space allocated was fifty cylinders.

\section{PHASE II AND THE DEMERIT SYSTEM}

Phase II was to see the on-line processing of loans and returns, the master file being updated at the time of the transaction instead of in three-hour batches. The reserve collection was to be automated and go on-line. The recording of holds and the production of hold slips for patrons and books was to be fully automated. Detailed statistics of the use of the reserve collection were to be obtained.

One of the major objectives of Phase II was the replacement of the fines system by a demerit system. Under the demerit system a patron would accrue penalty points for the length of time a book was overdue. After a certain level was reached, a warning notice was to be sent out informing him that his privileges would be suspended if a particular level of points were exceeded. If he then exceeded this level, his borrowing privileges 
would be suspended, and whenever he subsequently presented his library card to take out books, the checking procedure in the program would find his borrower number invalid, prevent the transaction being recorded and print a message on a 2741 terminal giving the reason for suspension. After a given period, borrowing privileges would be restored, provided that overdue materials had been returned. At exam times, penalty points would accumulate more rapidly, as they would also for reserve materials which had short loan periods.

File organization for Phase II was to be altered from that of Phase I principally to allow easier retrieval and updating. A master index file would contain a brief record ( 26 bytes for class number, 4 bytes for relative address) for every cataloged book in the library. This index file would lead into the Loan Master File which would consist of variable length records: one fixed length portion of the class number and author-title, followed by varying numbers of fixed length sections giving details of the loan transaction. The number of the transaction sections would depend on the number of copies of the book which were on loan. Anticipated file sizes were 60 cylinders for the Master Index and 30 to 40 cylinders for the Loan Master File. The increase in file handling efficiency and in restarting with no lost data after system down-time were seen to compensate for the increase in space allocation.

\section{LOAN POLICY CHANGES}

Problems with the system of fines and proposals such as the demerit system led to the suggestion that a survey should be made of campus opinion on the library loan policy. An examination of the results of the questionnaire and the comments obtained led to the submission of a somewhat different loan policy to the Senate Library Committee. This policy, briefly, was a recall system with the two-week loan period changed to a semester loan period for general loan material, and retention of the current fines system for reserve materials until the implementation of Phase II. Failure to respond to recall was to be penalized by suspension of library service. The system was to be experimental for two semesters.

The decision to adopt a recall system had an immediate impact on system development for Phase II:

1. Specifications for Phase II needed to be reworked.

2. The demerit system was no longer required.

3. Interim procedures were required to handle the recall system until the inception of Phase II.

4. File size growth became unpredictable because it was not known whether all books would stay out until the end of the semester or be returned at more frequent intervals. This could indicate a file size of between 30,000 and 80,000 .

\section{REVISION OF THINKING ON ON-LINE CIRCULATION}

Two significant developments made it advisable for the library to re- 
consider its need for an on-line system in terms of both its benefits for the library and its economic justification.

The first development was, as indicated, the radical revision of library loan policy-namely, the proposed adoption of a semester loan period supported by a recall system.

The second was a detailed costing of the equipment requirements for Phase II of the on-line system, weighing the relative merits and costs of two alternative manufacturers. These costs have turned out to be significantly higher than originally anticipated.

Consequently, it was seen that the costing done for Phase II should be done again in the light of the new developments.

The original benefits of the on-line system were also reexamined.

1. Inventory Control-This still applied as far as the reserve collection was concerned. These statistics would have to be gained in some other way insofar as they are additional to the statistics now collected manually.

2. Inventory Usefulness-This was no longer a justification. By this time we had developed collection analysis programs which give a fine breakdown of the collection into separate disciplinary areas and give total volumes and book usage by borrower class in these areas. Further development of these programs could give more information; e.g. referencing the registration system files could give information correlating students, courses, and book usage.

3. Increase in Service-This was no longer a justification.

(a) The implementation of the recall system with its attendant suspension of privileges does not demand an on-line system for its operation as would the previously proposed demerit system. With a suspension of privileges for those owing over $\$ 25$ tested in early 1971 , we were operating a manual system of borrower control successfully, leading us to assume that the recall system's control system would similarly function well.

(b) Nobody ever complained that the information on the batch system was too old (eighteen hours old at maximum). We had even had messages (anonymous) left by frustrated users of the on-line terminals which could be paraphrased as: "what was wrong with the old system?"

4. Cooperation-This was no longer a justification. Extensions of the work on collection analysis mentioned in 2 above could help in the identification of high and low use items and thus provide an alternative way to save the estimated $\$ 800,000$ per year. Work on collection comparison between the three British Columbia universities is already underway in a tri-university task force.

5. Future Development-This was no longer a justification. Shelflist conversion should have been hastened by the abandoning of the on-line loan system insofar as resources would be freed to work on the conversion, which is of far greater importance to the future information 
handling capability of the library than knowing within four seconds whether or not a book is on loan-especially as the time taken in reshelving of books make this loan information prone to inaccuracy. It thus appeared that the reasons used to justify an on-line system were no longer valid, if, indeed, they ever were.

When examining the cost figures again in view of the proposed recall system, the amortization of the development and equipment costs no longer seemed possible. The cost of the batch and on-line system equipment is shown in Figures 1 and 2 for both IBM and Colorado Instruments (now Mohawk). It can be seen that the difference in equipment costs between the proposed batch system and Phase II would have been over $\$ 15,000$ per year. (Some of the savings in equipment rental has been used to microfilm the subject catalog for distribution to three floors in the library which do not have easy access to this catalog.) The manual procedures involved with fines which Phase II was to eliminate are now considerably reduced by the recall system. The development costs of Phase II have been replaced with the cost of returning to the old batch system in a slightly improved form. The cost of this, at the Computing Centre, was \$2,123.76.

It had been predicted that writing Phase II in Minerva and Marc IV (two high-level program language packages) would make considerable savings in the impact on Computing Centre operations. However, even taking this into account there still remains the development costs and at least $\$ 15,000$ per year for extra equipment. (The difference between the equipment costs for Phase I (Figure I) and Phase II (Figure 2).) See the appendixes for cost comparison and projections.

\begin{tabular}{|c|c|c|c|}
\hline Colorado ( 3 year lease) & Monthly & IBM & Monthly \\
\hline 3 C-DEKS @ \$131.29 & $\$ 393.87$ & 11031 A Terminal & \\
\hline \multirow{2}{*}{$\begin{array}{l}3 \text { C-DEK cable terminals } \\
\text { @ } \$ 2.14\end{array}$} & & 100.34 & $\$ 100.34$ \\
\hline & 6.42 & 11031 A Terminal & 105.35 \\
\hline \multirow{4}{*}{$\begin{array}{l}1 \text { Central Controller } \\
1 \text { Controller cable terminal } \\
\text { box } \\
2 \text { MAG tape-recorders }\end{array}$} & 137.25 & 11031 B Terminal & 64.12 \\
\hline & & 1 1034 Card Punch & 328.73 \\
\hline & $\begin{array}{r}2.25 \\
268.20\end{array}$ & $\begin{array}{l}\text { (includes educational } \\
\text { discount) }\end{array}$ & 598.54 \\
\hline & 807.99 & Service-free & \\
\hline \multirow[t]{2}{*}{ Discount@12\% } & 100.00 & \multirow{2}{*}{$\begin{array}{l}\text { Installation-equipment } \\
\text { already on site }\end{array}$} & \\
\hline & 707.99 & & \\
\hline
\end{tabular}

Installation-probably free Service Contractapproximately $\quad 122.00$ TOTAL COLORADO MONTHLY $\$ 829.99$ TOTAL IBM MONTHLY $\$ 598.54$

Fig. 1. Equipment Costs (1971) IBM vs Colorado, Phase I and Off-Line 


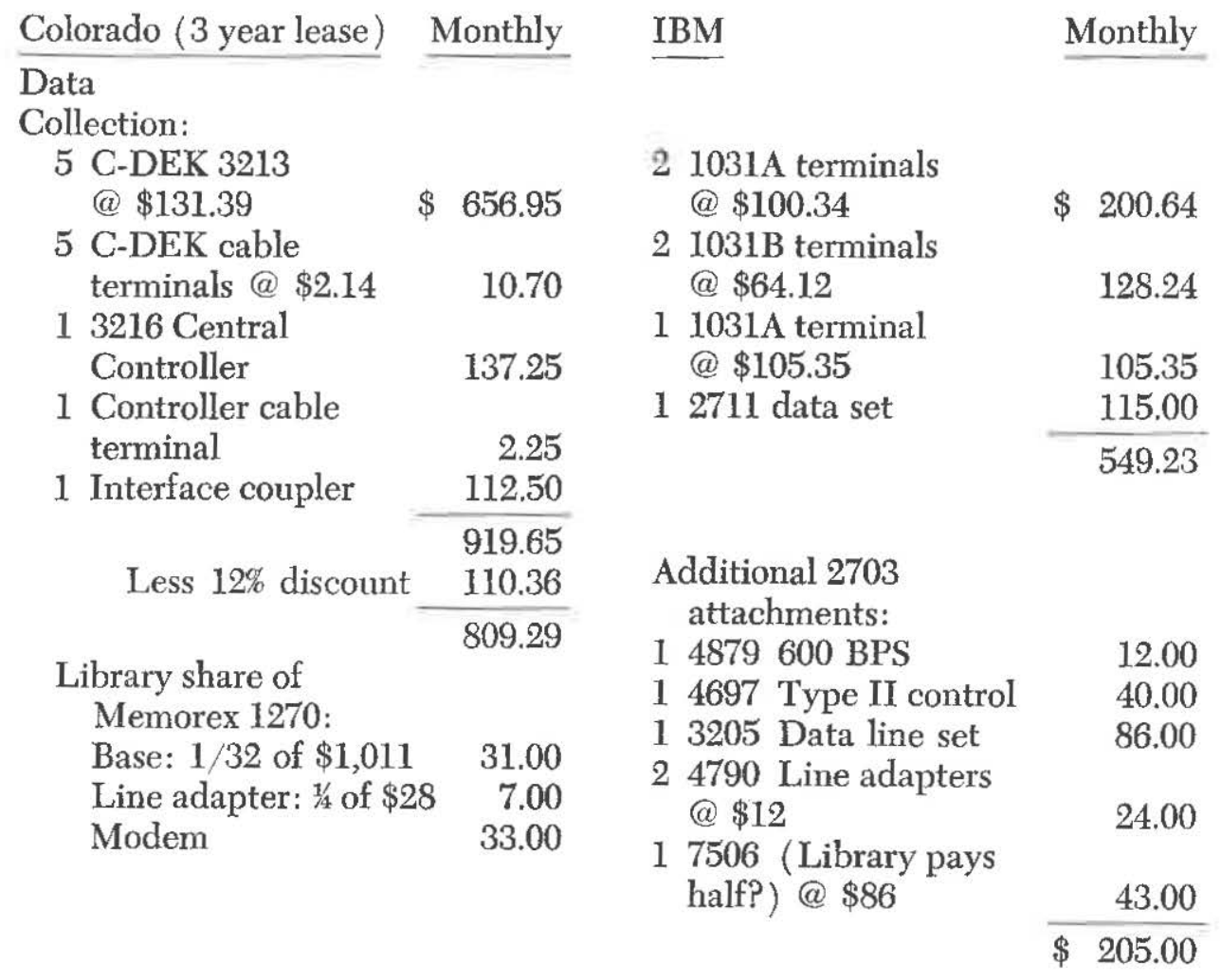

Back-up:

9-track mag-tape recorder with free switching RPQ

134.10

Switching RPQ

36.00

Back-up clock

98.21

328.73

Printers:

$22741 @ \$ 90.70$

181.40

$22741 @ \$ 90.70$

181.40

Display Terminals:

$42260 @ \$ 46.74$

186.96

42260 @ \$46.74

186.96

Share of 2848

311.10

Share of 2848

311.10

SYSTEMS

EQUIPMENT

TOTALS:

$\$ 1,693.85$

Service Contract:

Prime shift only

195.00

TOTAL MONTHLY

COST:

$\$ 1,888.85$

Installation and

Check-out:

$\$ 1,390.00$

Equipment Freight

Charges:

Approximately
Nil

$\$ 1,896.63$

$\$ 1,896.63$

$\$ \quad 100.00$

Fig. 2. Equipment Costs (1971) IBM vs Colorado, Phase II 


\section{THE PRESENT RECALL SYSTEM}

The recall system has been in operation since August 1971.

Its principal features are as follows:

That books be loaned for a period of one semester.

That they be subject to recall after a period of two weeks after borrowing.

That they become due on the last day of exams.

That there be a penalty for failure to respond to recall.

That there be a penalty for failure to return books after exams.

That the penalty be suspension of library privileges plus a $\$ 5.00$ fine. In the case of failure to respond to recall, the $\$ 5.00$ fine is levied five days after the recall notice is sent. In the case of failure to return books after exams, the fine is $\$ 1.00$ per day to a maximum of $\$ 25.00$, starting at the end of the semester. Listings of overdue books will be run during this period only, and a fine payment card produced and kept in the Loan Division. As in the first system, the fine payment card is used to cancel fines upon payment. The fine system and checking of delinquent borrowers is being successfully handled manually.

That privileges will be restored only when the patron has both returned the books and paid the fine.

The automated part of the system is similar to the original system described earlier except that fine and overdue notices are produced only at the semester end as mentioned.

The reaction of the staff handling the recall system has been favorable, as has been the reaction of patrons. Initial fears that a high percentage of the books in the collection would be out all semester and be returned en masse at the end have proved unfounded. The number of books out at any one time is often less than under the previous system. People seem to be returning books when they have finished with them and taking out fewer at a time; thus, browsing and usage are not affected. Books began returning at 2,000 per day on November 30,1971 in anticipation of the December 17 due date (Master File standing at around 34,000 books on loan at this point).

On December 19 only 4,864 books had not been returned. By December 29 this was down to 2,169, and by January 13, 1972 down to 394 .

Recalls have fluctuated between 35 and 130 per day and of these an average of 8 recalls per day have not been picked up by the recaller. By contrast, under the fines system, the daily production of fines, overdue, and hold notices was between 500 and 700 .

The total amount of fines from September 1, 1970 to November 17, 1970 was $\$ 11,021.32$. From September 6, 1971 to November 17, 1971 the figure was $\$ 2,405.03$, a difference of $\$ 8,616.29$. Thus, although people are making similar use of the library, judging by the circulation statistics, it is not costing them as dearly. 


\section{COSTS}

Comparative computer operating costs are shown in Table 1.

Table 1. Comparative Computer Operating Costs

Average Monthly Computer Cost

$\begin{array}{lll}\text { 1969-70 Old batch system } & \$ 3,100 & \text { IBM } 360-40 \\ 1970-71 \text { Phase I- on-line } & \$ 3,851 & \text { IBM 360-50 } \\ 1971 \text { Recall system, batch } & \$ 1,178 & \text { IBM } 360-50 \\ 1972-73 \text { Recall system, batch } & \$ 514 & \text { IBM } 370-155\end{array}$

The annual average cost of computer processing is now $\$ 6,168$ rather than the $\$ 19,320$ projected in Appendix 1. Staff salaries have risen in the two years since August 1971 and loans staff costs are now $\$ 33,200$ instead of $\$ 21,267$.

\section{TOTAL}

Total annual cost is now $\$ 6,168$ (computer time) $+\$ 7,182$ (equipment) $+\$ 33,200$ (loan staff and materials) $=\$ 46,550$. This is less than the projected annual cost of $\$ 57,994$.

The recall system certainly seems so far to be making the predicted savings, and the increase in good will in the university community is something we must also take into account on the credit side.

\section{CONCLUSION}

As is stressed so often in systems analysis theory, and sinned against so often in practice, a clear statement of objectives is required and a thorough cost/benefit analysis of all alternative solutions is needed to prevent unwanted solutions of unreal problems. A first question should be: "What are we really trying to achieve here?" rather than: "I wonder if we could apply system $\mathrm{x}$ in this situation?"

Automation is one of many possible solutions to a problem. An on-line system is one of many possible automated solutions.

The management aspects of the decisions in setting up an on-line system were referred to in "Reasons for Going On-line." The thought of taking the on-line system down again was born of a number of factors.

In the first place, feeling on campus caused the loan policy to evolve in a way not predictable at the time of system design.

In the second place, we learned that on-line systems are not to be treated lightly. They require a great deal of careful design and technical competence if they are to be as efficient as they are impressive. They embody concepts as different from batch processing as batch processing is from the manual system it may replace. For us, the result was escalating costs, and an on-line system design that could have been better and less costly.

The solution finally adopted was the result of considering what were seen to be the real requirements: maximum availability of materials with maximum convenience; and against the background of the library's general objectives, maximum cost-effective service in an era of tight budgets. 


\section{APPENDIX 1}

Annual Circulation System Cost Summary (as of August 1971)

\begin{tabular}{|c|c|c|c|c|c|c|c|}
\hline \multirow[b]{2}{*}{ Annual Costs } & \multirow{2}{*}{$\begin{array}{c}\text { Proposed } \\
\text { Batch } \\
\text { (With Recall) }\end{array}$} & \multirow{2}{*}{$\begin{array}{l}\text { Present On- } \\
\text { Line Phase I } \\
\text { (Without } \\
\text { Recall) }\end{array}$} & \multirow{2}{*}{$\begin{array}{c}\text { Phase II } \\
\text { Predicted } \\
\text { (With Recall) }\end{array}$} & \multicolumn{2}{|c|}{ Savings Over } & \multicolumn{2}{|c|}{$\begin{array}{c}\text { Losses Compared } \\
\text { With }\end{array}$} \\
\hline & & & & Phase I & Phase II & Phase I & Phase II \\
\hline Machine Time & $\$ 19,320$ & $\$ 37,150$ & $\$ 42,000$ & $\$ 17,830$ & $\$ 22,680$ & - & - \\
\hline \multicolumn{8}{|l|}{ Forms } \\
\hline Overdue Notices & 950 & 3,250 & 950 & 2,300 & - & - & - \\
\hline Fine Notices & 15 & 48 & 15 & 33 & - & - & - \\
\hline Printouts & 3,200 & 960 & 1,000 & - & - & $\$ 2,240$ & $\$ 2,200$ \\
\hline Postage for Overdues \& Fines & 3,530 & 12,000 & 3,530 & 8,470 & - & - & - \\
\hline Envelopes & 70 & 250 & 70 & 180 & - & - & - \\
\hline Postage for Holds/Recalls & 1,200 & - & 1,200 & - & - & 1,200 & - \\
\hline Punch Cards & 1,260 & 1,260 & - & - & - & - & 1,260 \\
\hline \multicolumn{8}{|l|}{ Loans Staff } \\
\hline Fines & 2,000 & 6,000 & 2,000 & 4,000 & - & - & - \\
\hline Stuffing Envelopes & 600 & 2,000 & 600 & 1,400 & - & - & - \\
\hline Looking up Addresses & 400 & 1,200 & 400 & 800 & - & - & - \\
\hline Reserves Staff & 18,267 & 18,267 & 14,763 & 一 & - & - & 3,504 \\
\hline \multicolumn{8}{|l|}{ Equipment } \\
\hline 1030 System & $7,182.48$ & $7,182,48$ & $14,606.04$ & - & $7,423.56$ & - & - \\
\hline 2260 Terminals & - & $1,682.64$ & $2,243.52$ & $1,682.64$ & $2,243.52$ & - & - \\
\hline Share of 2848 & - & $3,733.20$ & $3,733.20$ & $3,733.20$ & $3,733.20$ & - & - \\
\hline 2741 Terminals & - & - & $2,176.80$ & - & $2,176.80$ & - & - \\
\hline & & & & $\$ 40,428.84$ & $\$ 38,257.08$ & $\$ 3,440$ & $\$ 6,964$ \\
\hline
\end{tabular}

PHASE II $\$ 31,293$ 


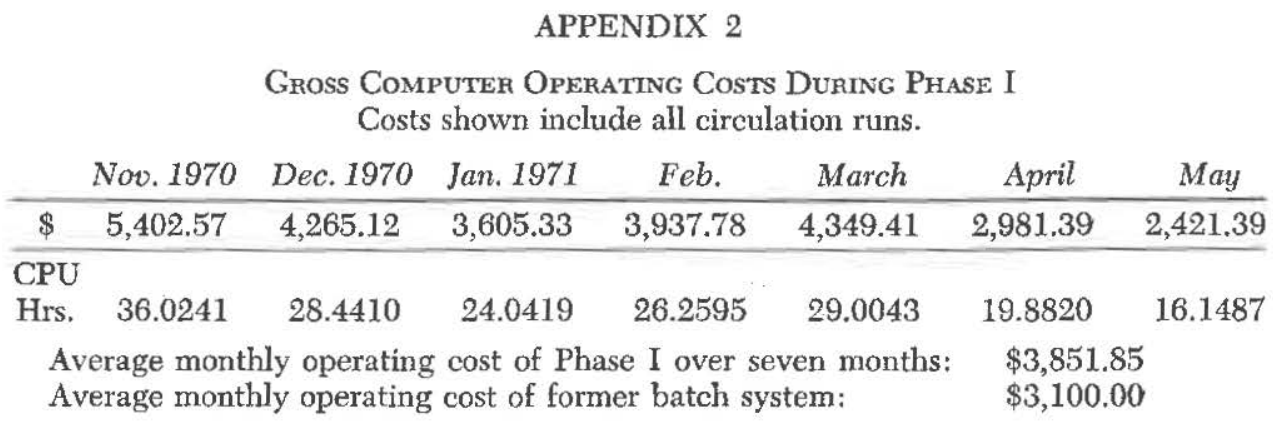

\section{APPENDIX 3}

Development Costs for Phase II Completion

Present system (Phase I) converted to Minerva with new file organization, etc. and interface to batch system.

\section{Systems}

Computing Centre

Library

Programming and systems tests

Est. Pacific Western Consulting (Minerva) at $\$ 150$ per day

\begin{tabular}{lr}
2 months & $\begin{array}{r}1,800 \\
7 \text { days }\end{array}$ \\
Subtotal & 200 \\
7 months & $\frac{2,000}{5,600}$ \\
5 days & -750 \\
Subtotal & $\begin{array}{r}8,350 \\
1,500\end{array}$ \\
& 550 \\
(10 days) & 350 \\
\hline 10,250 \\
\hline
\end{tabular}

Computer time (est.)

Forms, staff training

Parallel runs

Minerva Total

Phase II on-line

Systems

Computing Centre

IBM Support

Library Personnel

\begin{tabular}{|c|c|}
\hline 13 months & 11,700 \\
\hline 48 days & 1,900 \\
\hline Subtotal & 15,000 \\
\hline 21 months & 16,800 \\
\hline 10 days & 1,500 \\
\hline Subtotal & 33,300 \\
\hline & 10,000 \\
\hline & 1,000 \\
\hline & 1,15 \\
\hline & 1,30 \\
\hline & 46,755 \\
\hline & 57,005 \\
\hline
\end{tabular}

Programming and Systems tests

Pacific Western Consulting

Computer time (est.)

Forms, staff training

Parallel runs ( 33 days at $\$ 35$ per day)

Equipment rental (@ $\$ 1,200$ per month additional)

Total development Phase II

46,755

Total System Development

(Already spent-in addition): $\$ 11,576$ 


\section{APPENDIX 4 (a)}

Original Circulation System

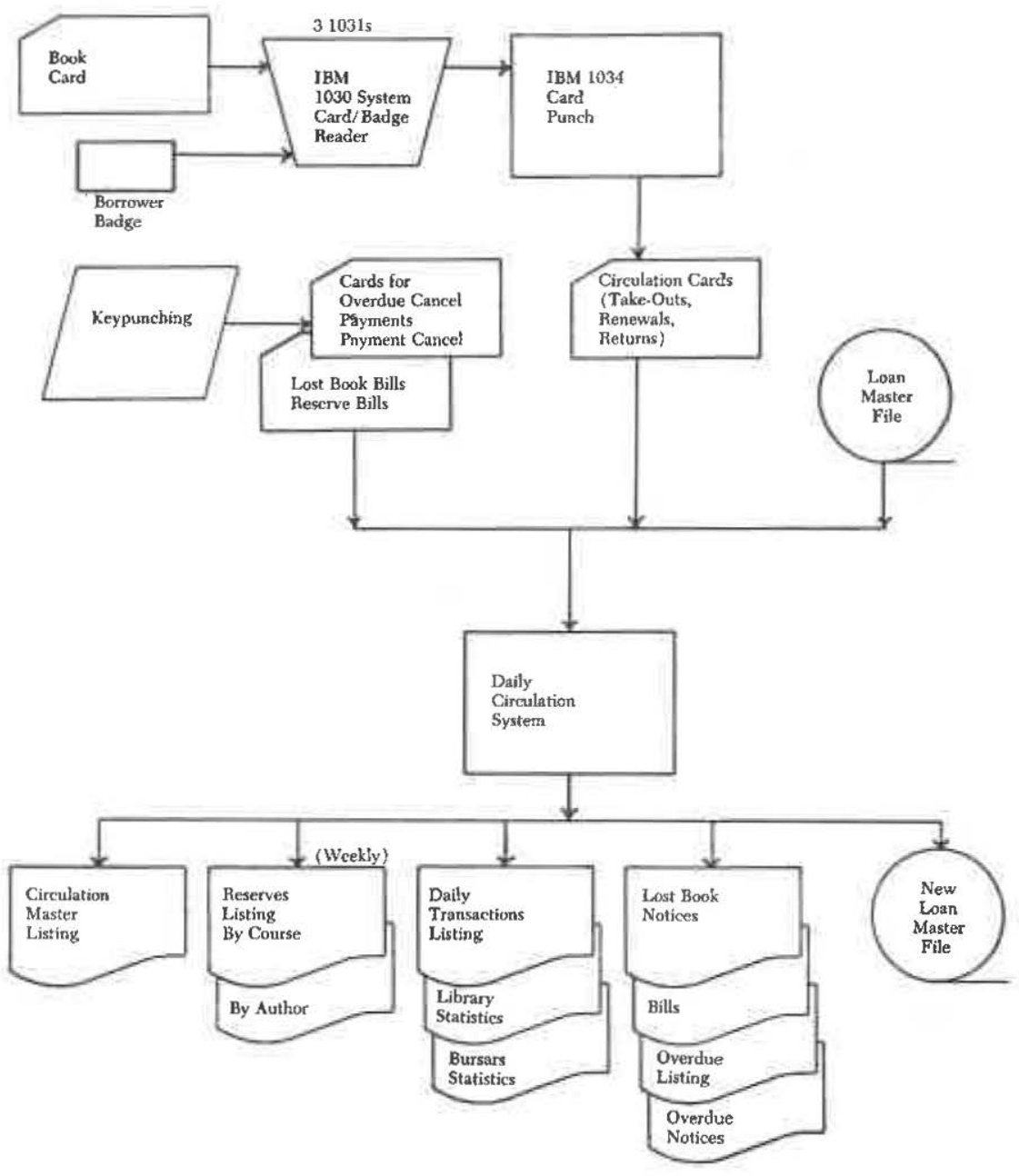




\section{APPENDIX 4 (b)}

Phase I

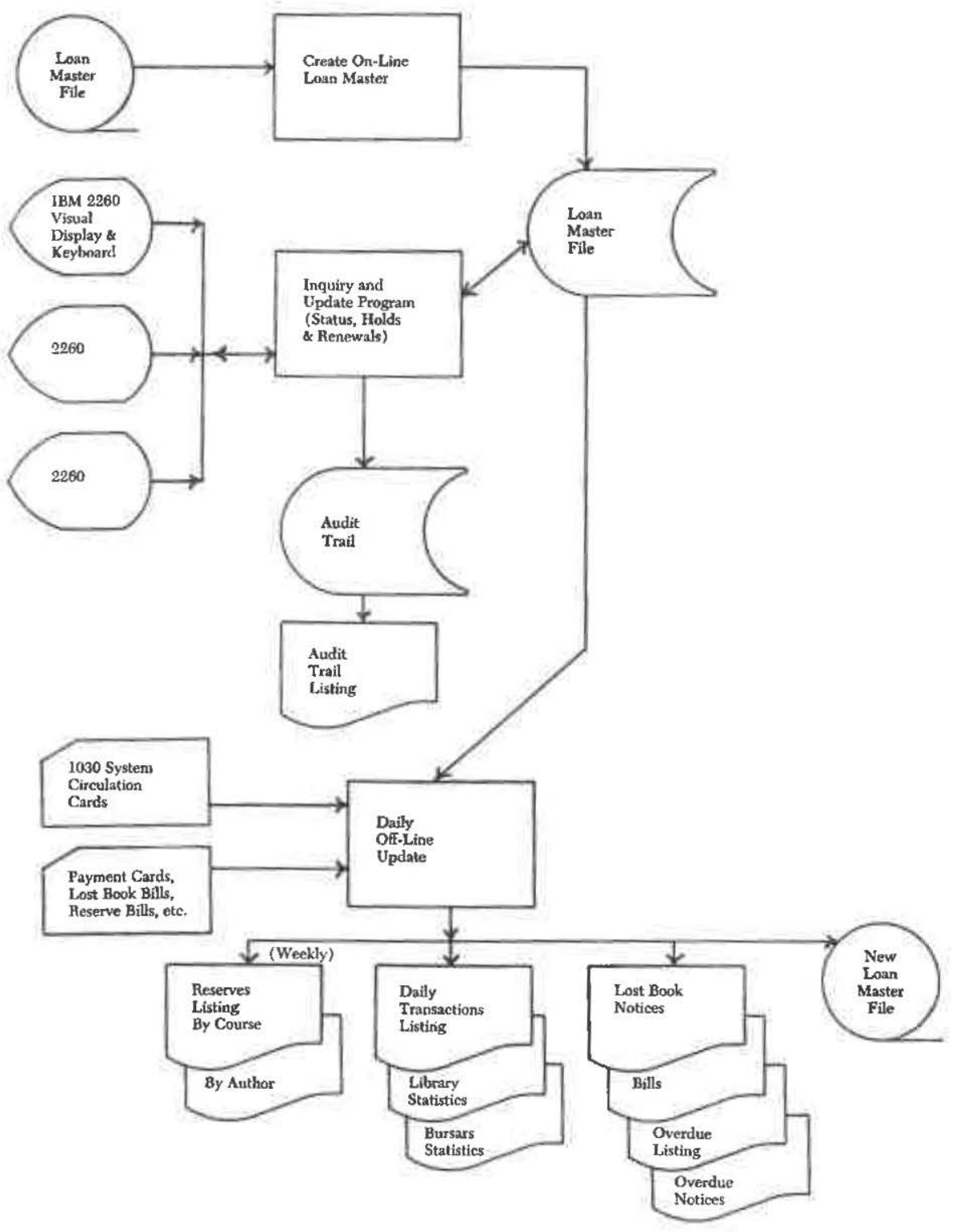




\section{APPENDIX 4 (c)}

Proposed Phase II

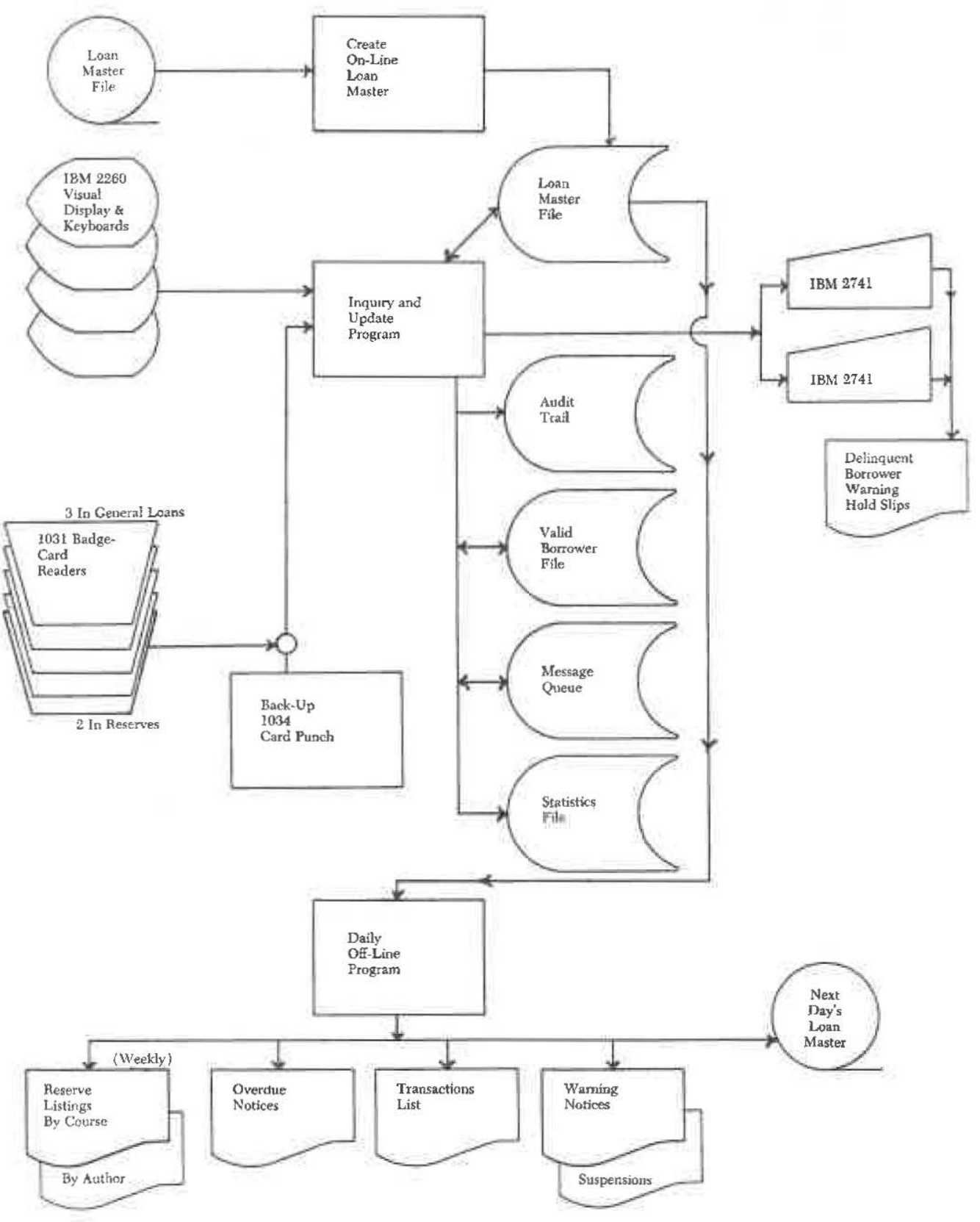


102 Journal of Library Automation Vol. 6/2 June 1973

\section{APPENDIX 4 (d)}

Present System

(Manual Recall and Fine Control System Not Shown.)

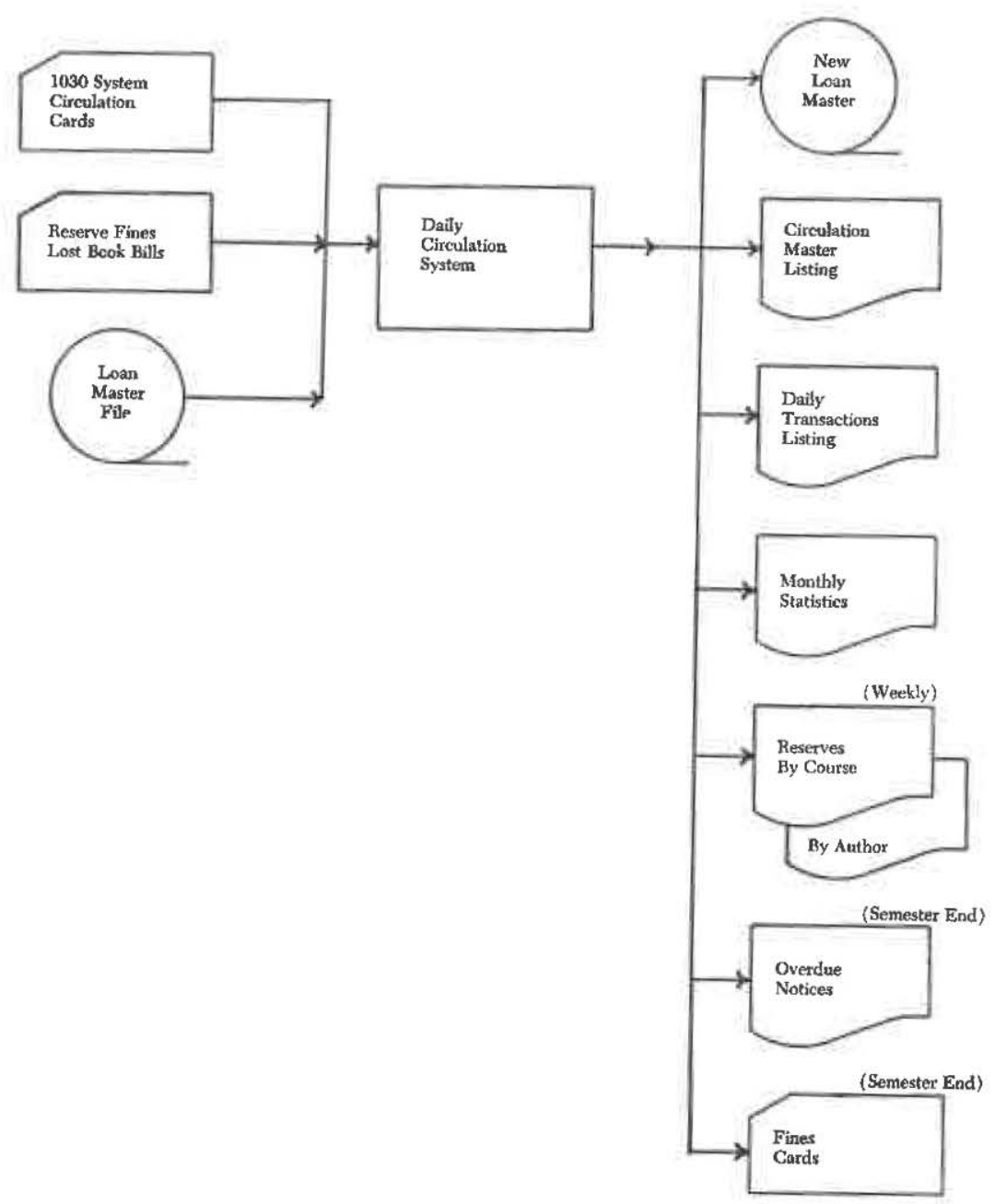

